\title{
Fungal grass endophytes, grass cultivars, nitrogen deposition and the associations with colonising insects
}

\author{
J. KRAUSS ${ }^{1,2}$, S.A. HÄRRI ${ }^{1}$, L. BUSH ${ }^{3}$, S.A. POWER ${ }^{4}$ and C.B. MÜLLER ${ }^{1}$ \\ ${ }^{I}$ Institute of Environmental Sciences, University of Zürich, Winterthurerstrasse 190, CH-8057 Zürich, Switzerland \\ ${ }^{I}$ Department of Animal Ecology I, Population Ecology, University of Bayreuth, Universitätsstrasse 30, D-95447 Bayreuth, Germany \\ ${ }^{3}$ Department of Plant and Soil Sciences, University of Kentucky, Lexington, KY 40546-0091, USA \\ ${ }^{4}$ Division of Biology, Imperial College London, Silwood Park Campus, Ascot, Berkshire SL5 7PY, U.K.
}

jkrauss@uwinst.unizh.ch

\begin{abstract}
Fungal endophytes associated with pasture grasses can have community-wide effects on insect consumers. Here we asked the question to what degree endophyte infection, simulated nitrogen deposition and grass cultivar influence the abundance of colonising herbivores and their natural enemies. In a fully randomised field experiment, consisting of four Lolium perenne monocultures of known endophyte infection status and a nitrogen addition treatment, we determined the abundance of colonising aphids, their parasitoids and predators, and other grass herbivores. The three colonising cereal aphid species did not respond to endophyte infection, possibly because peramine concentrations were relatively low $(3.9 \mu \mathrm{g} / \mathrm{g})$. There was a significant interaction between nitrogen addition and plant cultivar on the abundance of Sitobion avenae, suggesting a cultivar-specific response to nitrogen addition. Aphid predators were affected by an interaction between endophyte and plant cultivar, but abundance of aphid parasitoids and other grass herbivores was not affected by any treatment. The fungus Claviceps purpurea naturally infected our experimental plants and infection rates differed among cultivars and were more likely to occur on endophyte-infected plants, in particular on wild-type Samson. We conclude that strong effects of endophytes on insect abundance may not occur in systems built upon $L$. perenne because overall peramine levels rarely reach threshold levels for insect toxicity.
\end{abstract}

Keywords: fungal endosymbionts, multitrophic interactions, field experiment, insect food webs, alkaloids

\section{Introduction}

Ubiquitous fungal endophytes in cool-season grasses have the potential to affect food web structure (Omacini et al. 2001) and ecosystem function (Rudgers et al. 2004) by the production of herbivore-toxic alkaloids. Nevertheless, indirect interactions among endophytic fungi of the genus Neotyphodium, grass herbivores, and their natural enemies and interactions with other fungi remain largely unclear(Müller \& Krauss 2005; but see Krauss et al. 2007). Such multitrophic interactions may be influenced by the inconspicuous endophyte, as well as environmental factors and their interplay with fungal endophytes.

One important environmental factor known to influence herbivore communities is enhanced nitrogen input (Krauss et al. 2007). Enhanced nitrogen deposition is one of the major threats to biodiversity at a global scale (Vitousek et al. 1997). In the study region around Zürich, Switzerland, atmospheric nitrogen deposition was 15 - $25 \mathrm{~kg} / \mathrm{ha}$ per year in 2000 (BAFU: http:// stratus.meteotest.ch/lugis/map/). In other European regions, deposition rates can be much higher (Gundersen et al. 1998). As nitrogen is a main component of the alkaloids produced by the endophyte-plant association, there is the potential for differential effects of increased nitrogen deposition in endophyte-infected plants compared to uninfected plants. Differences in foliar nitrogen and alkaloid levels also have the potential to modify food web structures and thus the relationship between plants, fungi and associated insect communities.

In addition to environmental factors, the genetic background of the plant harbouring endophytes can also affect associated herbivores and predators (Meister et al. 2006; Krauss et al.

Table 1 Analyses of effects of endophyte infection, plant cultivar and nitrogen addition on the abundance of herbivores, parasitoids, predators and the fungal pathogen Claviceps purpurea. The mean abundances pooled for each cultivar for nitrogen treatment and infection status are shown in Figures 1 and $2 .{ }^{* \star}{ }^{*} \mathrm{P}<0.001 ;{ }^{\star \star} \mathrm{P}<0.01 ;\left(^{\star}\right) \mathrm{P}<0.1 ; \mathrm{n} . \mathrm{s}$. $\mathrm{P} \geq 0.1$

\begin{tabular}{|c|c|c|c|c|c|c|}
\hline $\begin{array}{l}\text { Predictor / } \\
\text { Response }\end{array}$ & Aphids & $\begin{array}{l}\text { Primary } \\
\text { parasitoids }\end{array}$ & $\begin{array}{l}\text { Secondary } \\
\text { parasitoids }\end{array}$ & Grass feeders & Predators & $\begin{array}{l}\text { C. purpurea } \\
\text { infection rate }\end{array}$ \\
\hline ss & $\mathrm{F}_{9,72}=84.17^{* * *}$ & $F_{9,72}=23.09 * * *$ & $\mathrm{~F}_{9,72}=37.15^{* \star *}$ & $F_{9,72}=29.87^{* \star *}$ & $\mathrm{~F}_{9,72}=9.14^{\star \star \star}$ & $F_{9,72}=11.41^{* \star *}$ \\
\hline Infection & $F_{1,72}=0.13$ n.s. & $F_{1,72}=1.12$ n.s. & $F_{1,72}=0.04$ n.s. & $F_{1,72}=0.41$ n.s. & $F_{1,72}=0.45$ n.s. & $F_{1,72}=5.47 *$ \\
\hline Nitrogen & $F_{1,72}=0.39$ n.s. & $\mathrm{F}_{1,72}=1.83$ n.s. & $F_{1,72}=1.34$ n.s. & $F_{1,72}=0.07$ n.s. & $F_{1,72}=0.19$ n.s. & $F_{1,72}=0.00$ n.s. \\
\hline Cultivar & $\mathrm{F}_{3,72}=2.72\left(^{*}\right)$ & $\mathrm{F}_{3,72}=2.60\left(^{*}\right)$ & $F_{3,72}=1.54$ n.s. & $\mathrm{F}_{3,72}=0.43$ n.s. & $\mathrm{F}_{3,72}=0.05$ n.s. & $\mathrm{F}_{3,72}=12.40^{* \star *}$ \\
\hline Infectio & $F_{1,72}=0.22$ n.s. & $\mathrm{F}_{1,72}=0.57$ n.s. & $F_{1,72}=0.14$ n.s. & $F_{1,72}=0.00$ n.s. & $F_{1,72}=0.01$ n.s. & $F_{1,72}=1.29$ n.s. \\
\hline Infection $x$ cultivar & $F_{3,72}=0.33$ n.s. & $\mathrm{F}_{3,72}=0.42$ n.s. & $\mathrm{F}_{3,72}=0.59$ n.s. & $\mathrm{F}_{3,72}=0.58 \mathrm{n} . \mathrm{s}$ & $\mathrm{F}_{3,72}=3.59$ * & $F_{3,72}=2.17\left(^{*}\right)$ \\
\hline Nitrogen $x$ cultivar & $\mathrm{F}_{3,72}=3.96$ * & $F_{3,72}=0.23$ n.s. & $\mathrm{F}_{3,72}=0.58$ n.s. & $\mathrm{F}_{3,72}=1.16$ n.s. & $\mathrm{F}_{3,72}=0.97$ n.s. & $\mathrm{F}_{3,72}=0.15$ n.s. \\
\hline $\begin{array}{l}\text { Infection } x \text { nitrogen } \\
x \text { cultivar }\end{array}$ & $\mathrm{F}_{3,72}=1.13$ n.s. & $\mathrm{F}_{3,72}=0.64$ n.s. & $\mathrm{F}_{3,72}=0.75$ n.s. & $\mathrm{F}_{3,72}=0.33$ n.s. & $\mathrm{F}_{3,72}=0.95$ n.s. & $\mathrm{F}_{3,72}=0.60$ n.s. \\
\hline
\end{tabular}


Figure 1 Effects of endophyte infection and nitrogen addition on a) aphid, b) primary parasitoid and c) secondary parasitoid abundances, for four cultivars of Lolium perenne. Aphid numbers showed a significant interaction between nitrogen addition and cultivar; all other tests were statistically non-significant (see also Table 1). Infection level E- (absent), $\mathrm{E}+$ (present); nitrogen addition N- (control), N+ (80 kg/ha per year); Grass cultivar - Imp, Nui, Pac, Sam.
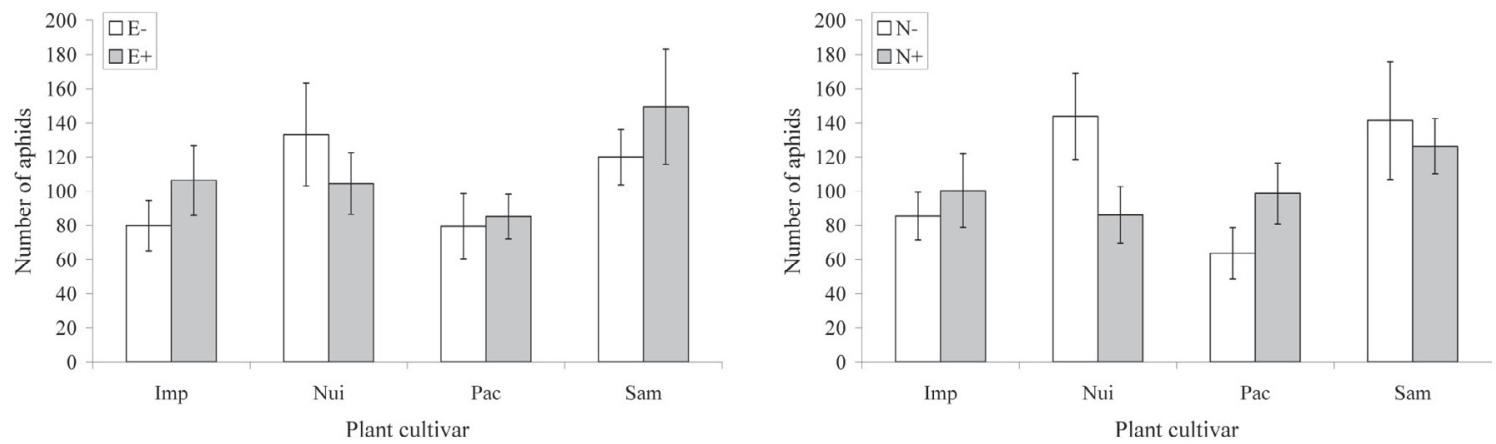

b)
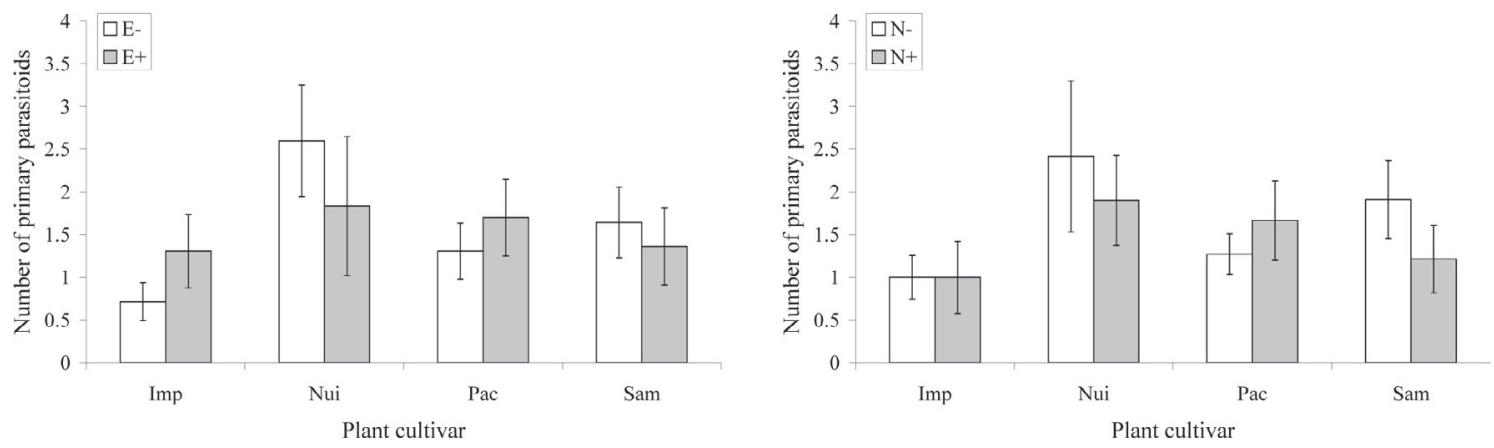

c)
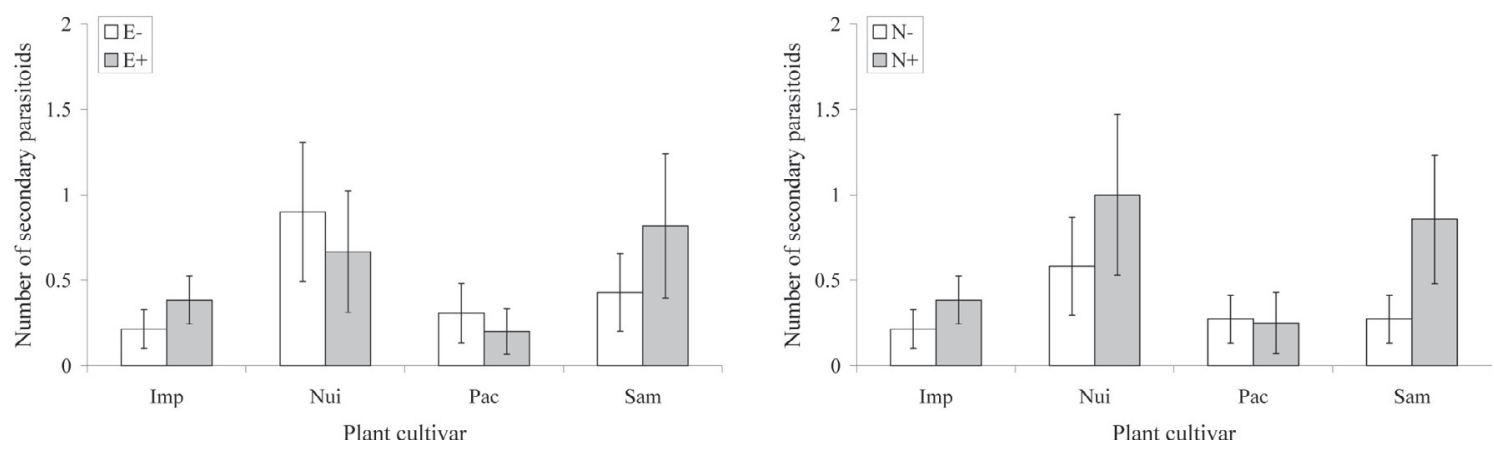

2007). Different, economically important grass cultivars were used to represent a range of genetic backgrounds of the grass. The aim of our study was to evaluate the importance of grass cultivar, endophyte presence and simulated atmospheric nitrogen deposition, and interactions among these factors, for multitrophic insect consumer interactions.

\section{Methods}

\section{Experimental design}

Endophyte-infected and endophyte-free Lolium perenne seeds of four different grass cultivars Imp (Lolium x boucheanum, Grassland Impact), Nui (L. perenne Grassland Nui), Pac ( $L$.

perenne Grassland Pacific) and Sam (L. perenne, Grassland Samson, wild type) were sown in 112 randomised experimental plots of $0.5 \times 0.5 \mathrm{~m}$, spaced at a distance of $0.5 \mathrm{~m}$, at an experimental field site near the University of Zürich, Switzerland. We seeded $2.0 \mathrm{~g}$ of seeds (approx. 750 seeds) per plot in spring 2003 and started to add nitrogen to half of the plots in a factorial manner 1 year later, at the end of April 2004. Twice a month $0.239 \mathrm{~g} \mathrm{NH}_{4} \mathrm{NO}_{3}$ dissolved in $1.0 \mathrm{~L}$ water was added to each nitrogen treatment plot, while control plots received the same amount of water. Nitrogen treatments equated to an annual input of $80 \mathrm{~kg} / \mathrm{ha}$.

Thirty seeds of each cultivar and infection status were stained and microscopically examined before seeding. Uninfected seeds 
Figure 2 Effects of endophyte infection and nitrogen addition on a) grass feeding aphids b) predator abundances and c) Claviceps purpurea infection rate, for four cultivars of Lolium perenne. The interaction between endophyte infection and plant cultivar was significant for predator numbers. The infection rate of $C$. purpurea was significantly affected by endophyte and cultivar treatments. All other tests were statistically non-significant (see also Table 1). Infection level E(absent), E+ (present); nitrogen addition N- (control), N+ (80 kg/ha per year); Grass cultivar - Imp, Nui, Pac, Sam.
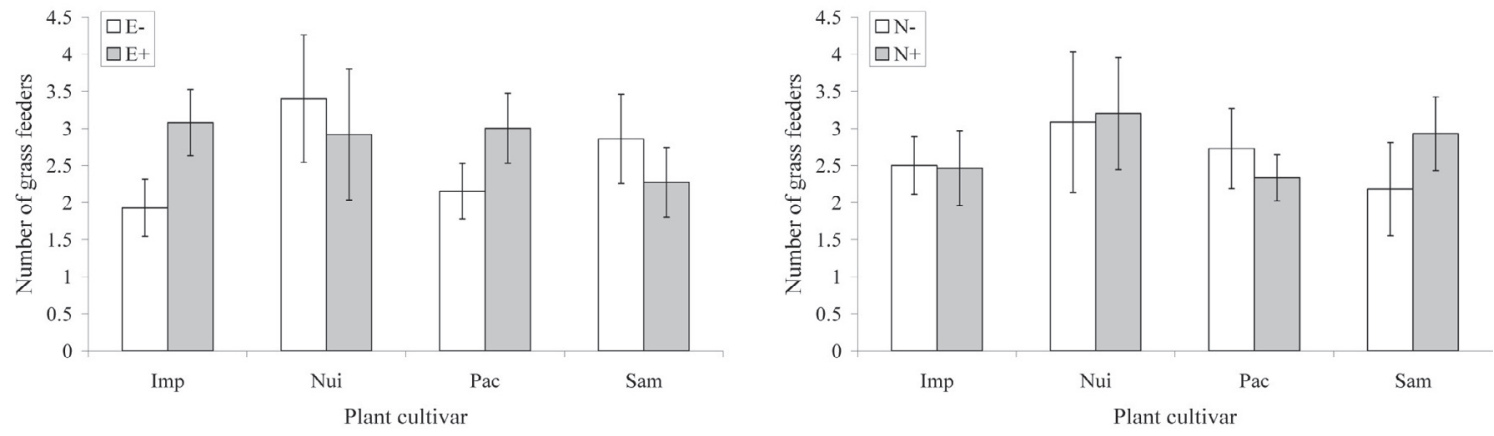

b)
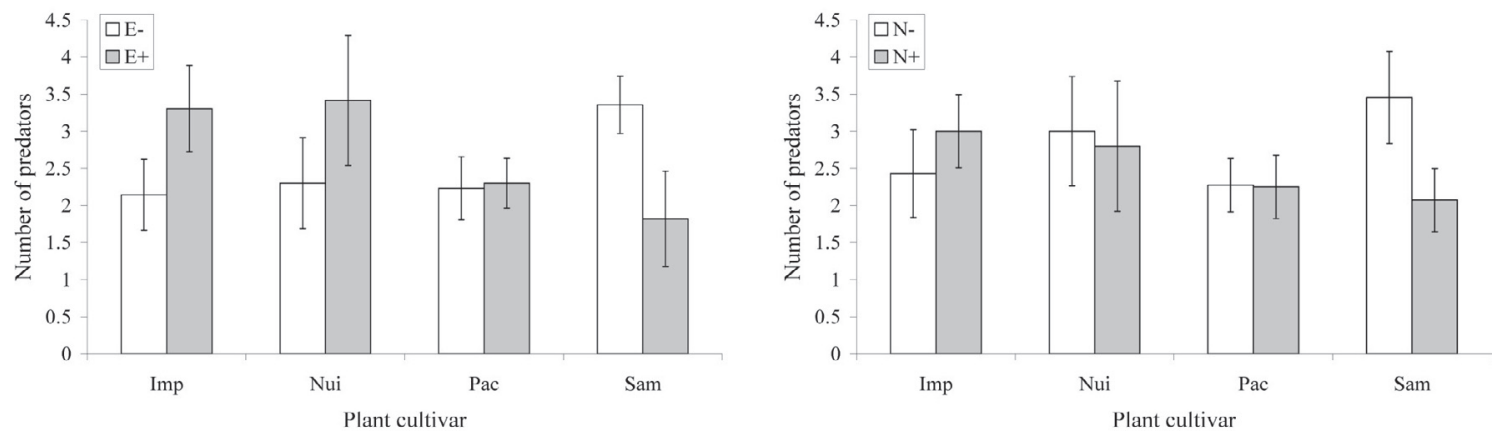

c)
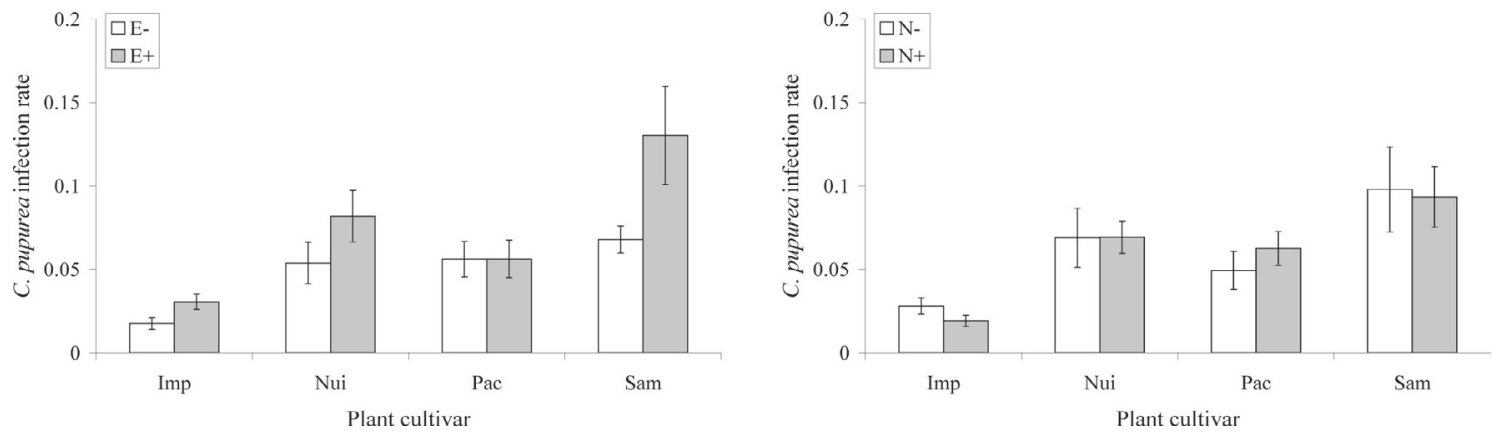

did not contain any endophyte hyphae, while infected seeds had an average infection level of $85 \%$ (Imp: 97\%, Nui 67\%, Pac $83 \%$, Sam 93\%, see Meister et al. 2006). Immunoblot assays of at least 50 plants with a minimum age of 2 weeks were conducted in a glasshouse experiment with the "Phytoscreen field tiller endophyte detection kit" by Agrinostics Ltd. Co. (http://www. agrinostics.com/) and revealed positive infection levels for less than $0.02 \%$ of uninfected plants and $69 \%$ of infected plants (Imp: 46\%, Nui 78\%, Pac 66\%, Sam 85\%).

Counts of aphids, aphid predators and grass herbivores were conducted six times between 12 May and 27 July 2004, covering the main aphid season on grasses. Insects were counted on fifty randomly chosen grass stems, with ears when available,

on each occasion. On two occasions in July, we collected all aphid mummies and reared all resulting primary and secondary parasitoids. From each plot, five flowering shoots were harvested on August 42004 for peramine analysis (for details of peramine analyses see Krauss et al. 2007). An assessment of naturally occurring Claviceps purpurea fungal infection was carried out on the 18 August 2004. This involved visual assessment of the presence of dark fungal sclerotia on flowering spikes and calculation of the ratio of infected to uninfected shoots per plot.

\section{Statistical analyses}

All statistical analyses were conducted using R (version 2.1.1). General linear models with the predictor variables $(i)$ plant 
cultivar, (ii) endophyte infection and (iii) nitrogen treatment, and all interactions were calculated. We used trend surface analyses to correct for possible spatial trends within our experimental field (Legendre \& Legendre 1998). Response variables were transformed when necessary to meet assumptions of normality and homoscedasticity. The count data for aphids, parasitoids, herbivores and predators were pooled over all sampling dates and square-root transformed. Arithmetic means and standard errors of back-transformed data are given throughout the text and in all figures.

\section{Results}

Across our experiment we found strong spatial effects on all response variables. The peramine analyses of plants of each plot at the end of the experiment indicated that 97 of the 112 plots had the expected infection status. Plots with measurable peramine levels indicated infection by the fungal endophyte; plots with infected plants that did not contain peramine and plots with uninfected plants with measurable peramine were excluded from further analyses. The peramine concentration in infected plants was $3.91 \pm 0.36 \mu \mathrm{g} / \mathrm{g}$ and did not differ between nitrogen addition $\left(\mathrm{F}_{1,29}=0.00, \mathrm{P}=0.994\right)$ and cultivar $\left(\mathrm{F}_{3,29}=0.68, \mathrm{P}=0.570\right)$ treatments, and there was no significant interaction between cultivar and nitrogen addition $\left(\mathrm{F}_{3,29}=0.33, \mathrm{P}=0.284\right)$.

In total, 10292 aphids were counted, of which 7177 individuals were Sitobion avenae, 2270 were Rhopalosiphum padi and 795 were Metopolophium festucae. There was a significant interaction between nitrogen addition and plant cultivar for aphid abundance (Table 1; Fig. 1a). This result mainly reflects the relationship seen for the most abundant aphid species $S$. avenae $\left(\mathrm{F}_{3,72}=3.50\right.$, $\mathrm{P}=0.020)$, the abundance of which was related to the number of ears per plot (Pearson correlation: $\mathrm{r}=0.399$; $\mathrm{P}<0.001$ ). This could indicate a difference in reaction to nitrogen addition for the different cultivars in terms of ear production. The other two aphid species $R$. padi and M. festucae feed on the stem or on leaves and showed no statistically significant treatment effects (results not shown). Similarly, neither primary parasitoid abundance (147 individuals, of which 131 were Aphidius rhopalosiphi), nor secondary parasitoid abundance (46 individuals) were significantly affected by our treatments (Fig 1b, c). The abundances of non-aphid grass herbivores (259 individuals) belonging to the bug genus Stenodema (214 individuals) and further bug and beetle species, were also unaffected by treatments (Fig. 2a; Table 1). There was a statistically significant interaction between endophyte infection and plant cultivar for total number of arthropod predators (256 individuals, represented by ladybirds, spiders, bugs, beetles, syrphids and chrysopids) (Fig. 2b; Table 1). Numbers were lower on the infected wild-type cultivar Sam, compared to the uninfected Sam. The reverse pattern occurred on the Imp cultivar, while for the remaining two cultivars no such effect was found (Fig. 2b).

The infection rate by $C$. purpurea was significantly higher in endophyte-infected plants compared to that of endophyte-free plants; plant cultivar strongly influenced $C$. purpurea infection, with highest rates of infection by C. purpurea on the endophyteinfected wild-type Sam (Fig. 2c; Table 1).

\section{Discussion}

Overall, we found very weak effects of the presence of the endophytic fungus on the abundance of insect herbivores and their natural enemies. Neither plant cultivar nor nitrogen addition modified these results. In a similar experiment involving higher levels of nitrogen addition in the same year and on the same plant cultivars, we were also unable to detect negative effects of endophytes on insect abundance (Krauss et al. 2007). The low peramine concentrations in both experiments (an average of $3.9 \mu \mathrm{g} / \mathrm{g}$ in the present experiment and $5.5 \mu \mathrm{g} / \mathrm{g}$ (unfertilised) or $8.0 \mu \mathrm{g} / \mathrm{g}$ (highly fertilised) in the second experiment) may not have reached toxic levels for insect herbivores and their natural enemies. Concentrations of $10.0 \mu \mathrm{g} / \mathrm{g}$ peramine were previously described as threshold toxin level to act as feeding deterrence to Argentine stem weevil (Keogh et al. 1996). Immunoblot assays revealed average infection rates of the infected cultivars of $69 \%$. The low peramine concentrations might therefore be partly explained by relatively low infection rates in the study plots with endophyte presence. Both our experiments were conducted at an experimental field site with naturally colonising insects and numerous possible indirect effects among these insect species. In contrast to the study of Krauss et al. (2007), in which aphid and parasitoid abundances were increased by the addition of agricultural levels of fertiliser, the lower rates of nitrogen addition in the present study, simulating atmospheric deposition processes did not increase insect abundance and, in fact, even decreased aphid abundance on one cultivar (Nui; see Fig. 1a).

The unexpected positive effect of endophyte presence on infection by $C$. purpurea has not been reported before. A lack of protection by the endophyte has been reported elsewhere in studies of endophyte-pathogen interactions (e.g. Hamilton \& Faeth 2005) but, in general, endophyte infection has been assumed to provide protection against pathogens (Gwinn \& Gavin 1992; Arnold et al. 2003). As the transmission of asexual Neotyphodium fungi to the next generation is only possible via seeds (Schardl et al. 2004), Neotyphodium fungi should have a cost when $C$. purpurea fungi destroy the host seeds.

We conclude that endophyte infection of grasses may occasionally cause complex interactions in insect food webs. However, in our experiment, endophyte presence, plant cultivar or elevated nitrogen inputs failed to have strong effects on abundance patterns of herbivorous insects and their natural enemies.

\section{ACKNOWLEDGEMENTS}

We thank Brian Tapper for providing the seed material and Claudio de Sassi, Susanne Müller, Julia Nüscheler and Tobias Züst for assistance in the field. The study was financed by a grant from SNSF to CBM (631-065950).

\section{REFERENCES}

Arnold, A.E.; Mejia, L.C.; Kyllo, D.; Rojas, E.I.; Maynard, Z.; Robbins, N.; Herre, E.A. 2003. Fungal endophytes limit pathogen damage in a tropical tree. Proceedings of the National Academy of Science, USA 100: 15649-15654.

Gundersen, P.; Emmett, B. A.; Kjonaas, O. J.; Koopmans, C. J.; Tietema, A. 1998. Impact of nitrogen deposition on nitrogen cycling in forests: a synthesis of NITREX data. Forest Ecology and Management 101: 37-55.

Gwinn, K.D.; Gavin, A.M. 1992. Relationship between endophyte infestation level of tall fescue seed lots and Rhizoctonia zeae seedling disease. Plant Disease 76: 911-914.

Hamilton, C.E.; Faeth, S.H. 2005 Asexual Neotyphodium endophytes in Arizona fescue: A test of the seed germination and pathogen resistance hypothesis. Symbiosis 38: 69-85.

Keogh, R.G.; Tapper, B.A.; Fletcher, R.H. 1996. Distributions of the fungal endophyte Acremonium lolii, and of the alkaloids 
lolitrem B and peramine, within perennial ryegrass. New Zealand Journal of Agricultural Research 39: 121-127.

Krauss, J.; Härri S.A.; Bush, L.; Husi, R.; Bigler, L.; Power, S.A.; Müller, C.B. 2007.

Effects of fertiliser, fungal endophytes and plant cultivar on the performance of insect herbivores and their natural enemies. Functional Ecology doi:10.1111/j.1365-2435.2006.01216.x

Legendre, P.; Legendre, L. 1998. Numerical Ecology, 2nd ed. Elsevier, Amsterdam, The Netherlands.

Meister, B.; Krauss, J.; Härri, S.A.; Schneider, M.V.; Müller, C.B. 2006. Fungal endosymbionts affect aphid population size by reduction of adult life span and fecundity. Basic and Applied Ecology 7: 244-252.

Müller, C.B.; Krauss, J. 2005. Symbiosis between grasses and asexual fungal endophytes. Current Opinion in Plant Biology 8: 450-456.

Omacini, M.; Chaneton, E.J.; Ghersa, C.M.; Müller, C.B. 2001. Symbiotic fungal endophytes control insect host-parasite interaction webs. Nature 409: 78-81.

Rudgers, J.A.; Koslow, J.M.; Clay, K. 2004. Endophytic fungi alter relationships between diversity and ecosystem properties. Ecology Letters 7: 42-51.

Schardl, C.L.; Leuchtmann, A.; Spiering, M.J. 2004. Symbioses of grasses with seedborne fungal endophytes. Annual Reviews in Plant Biology 55: 315-340.

Vitousek, P.M.; Mooney, H.A.; Lubchenco, J.; Melillo J.M. 1997. Human Domination of Earth's Ecosystems. Science 277: 494-499. 